\title{
Composition of fatty acids in the maternal and umbilical cord plasma of adolescent and adult mothers: relationship with anthropometric parameters of newborn
}

\author{
Olívia RC Oliveira', Michelle G Santana', Flávia S Santos', Felipe D Conceição', Fátima LC Sardinha',
} Glória V Veiga ${ }^{2}$ and Maria G Tavares do Carmo ${ }^{1,3^{*}}$

\begin{abstract}
Background: Considering the importance of long chain polyunsaturated fatty acids to fetal development and the lack of studies that have compared the status of fatty acids between adolescents and adults mothers, the purpose of this study was to evaluate the composition of fatty acids in maternal and umbilical cord plasma from adolescent and adults mothers.

Methods: Forty pregnant adolescents and forty pregnant adults were selected to assess the distribution profile of fatty acids in the maternal and umbilical cord plasma. Quantification of fatty acids in the total lipids of the sample groups was performed through the use of gas-liquid chromatography.

Results: The maternal and umbilical cord plasma of the adolescents showed a greater concentration of AA than did that of the adults $(P<0.05)$. However, a greater percentage of EPA was found in the umbilical cord plasma of the adults $(P<0.05)$. DHA in the plasma of the adolescent mothers correlated positively to birth weight and head circumference.

Conclusions: This suggests that in situations of greater nutritional risk, as in adolescent pregnancy, n-3PUFA concentrations have a greater influence on the proper development of newborns. Moreover, variations in fatty acid concentrations in the maternal and cord plasma of adolescents and adults may indicate that pregnancy affects the LC-PUFA status of adults and adolescents in distinct ways.
\end{abstract}

Keywords: Fatty acids, Pregnancy, Adolescence, Adulthood, Newborn

\section{Background}

The essential fatty acids (EFAs), linoleic acid (LA) and $\alpha$-linolenic acid (ALA), and their long-chain derivatives (long-chain polyunsaturated fatty acids - LC-PUFA) have been identified as important determinants of fetal growth and development [1]. However, EFAs cannot be synthesized by mammalian tissue due to a lack of $\Delta 15$ and $\Delta 12$ desaturase enzymes and must be obtained

\footnotetext{
* Correspondence: tcarmo@editema.com.br

${ }^{1}$ Nutritional Biochemical Laboratory, Josué de Castro Institute of Nutrition, Federal University of Rio de Janeiro, Rio de Janeiro, Brazil

${ }^{3}$ Instituto de Nutrição Josué de Castro, UFRJ - Laboratório de Bioquímica Nutricional, Av. Brigadeiro Trompowski, s/n - CCS, Bloco J, $2^{\circ}$ andar, Cidade Universitária, llha do Fundão, Cep.: 21941-590, Rio de Janeiro, Brazil Full list of author information is available at the end of the article
}

through dietary intake [2]. Although human beings are incapable of performing de novo $\mathrm{n}-3$ and $\mathrm{n}-6$ fatty acid synthesis [3], they are able to desaturate and elongate them by way of other enzymes, transforming LA to archidonic acid (AA) and ALA to eicosapentaenoic acid (EPA) and docosahexaenoic acid (DHA) [4].

AA is fundamental for fetal growth [5] and DHA, in particular, plays an important role in brain and retina formation, development, and functioning during pregnancy and the early years of life. Among the n-3 series of fatty acids, DHA is found in the greatest abundance in the central nervous system of mammals and is especially concentrated in the phospholipids of the cerebral

\section{Biomed Central}

(c) 2012 Oliveira et al.; licensee BioMed Central Ltd. This is an Open Access article distributed under the terms of the Creative Commons Attribution License (http://creativecommons.org/licenses/by/2.0), which permits unrestricted use, distribution, and reproduction in any medium, provided the original work is properly cited. 
grey matter membrane and the visual components of the retina [6].

Since the publishing of a consensus in 2007, it has been recommended that pregnant and lactating women consume a daily average of $0.2 \mathrm{~g}$ of DHA [7], which is associated with having a beneficial effect on the development of visual acuity and cognitive function, among other neural functions in infants [8].

It is noteworthy that the n-6 and n-3 fatty acids accumulated in the fetus are essentially derived from the mother by way of placental transfer [9]. Thus, maternal dietary intake of these fatty acids should be enough to guarantee adequate availability to the fetus [10].

Trans fatty acids $(t \mathrm{FA})$ are unsaturated and have at least one double bond in the trans configuration. They are primarily the result of the industrial hydrogenation of vegetable oils and are not synthesized by humans [11]. Like EFAs and LC-PUFAs, trans, too, are transferred to the fetus. However, they can impair fetal development [12].

Van Eijsden et al. [13] found a positive association between birth weight and LC-PUFA concentrations in maternal plasma during early pregnancy. The authors suggest that the dimensions of newborns may be optimized by maternal LC-PUFA intake during pregnancy.

Several studies [14-16] have identified poor dietary habits in adolescents, predominantly the high consumption of foods rich in saturated fatty acids (SFA) and $t$ FA (like cookies, chocolate, and ice cream, among others). Furthermore, fish is included in the least-frequentlyconsumed-food group, which contributes to the findings of inadequate levels of $n-3$ series fatty acids [17]. Thus, adolescents are often referred to as the age group with the highest prevalence of nutritional deficiency [18].

In this context, adolescent pregnancy is associated with an increase in risk for metabolic and nutritional status problems as compared to pregnancy during adulthood [19]. Adolescent mothers are at greater risk for having children with low birth weights, which is associated with neonatal mortality [20]. Seen in this light, the proposition of this study is to compare the fatty acid profile in adolescent and adult mothers, in maternal and fetal biological compartments, and its relationship to the growth parameters of newborns in Brazil.

\section{Results}

The average age of the pregnant adolescents was $16.7 \pm$ 1.4 years, while that of the adults was $28.3 \pm 5.7$ years. The socioeconomic and demographic characteristics of the group of women studied are shown in Table 1. Analysis of the numbers related to per capita income greater than or equal to one minimum-wage salary indicated a significant difference $(\mathrm{P}<0.05)$ between adolescent and adult mothers. Furthermore, more than half the adolescents evaluated (55.6\%) reported having left to study due to their pregnancy.

Table 1 Characterization of adolescent and adult mothers regarding the socio-economic, demographic and prenatal care variables

\begin{tabular}{|c|c|c|c|c|}
\hline \multirow[t]{2}{*}{ SOCIO-ECONOMIC VARIABLES } & \multicolumn{2}{|c|}{ Adolescents } & \multicolumn{2}{|c|}{ Adults } \\
\hline & n (\%) & $\mathrm{Cl} 95 \%$ & n (\%) & $\mathrm{Cl} 95 \%$ \\
\hline \multicolumn{5}{|l|}{ Per capita family income ${ }^{1}$} \\
\hline$<1$ per capita minimum wage ${ }^{2}$ & $25(80.6)$ & {$[62.5-92.5]$} & $20(52.6)$ & {$[35.8-69.0]$} \\
\hline$\geq 1$ per capita minimum wage ${ }^{2}$ & $6(19.4)$ & {$[7.4-37.5]$} & $18(47.4)$ & {$[40.0-64.2]^{*}$} \\
\hline \multicolumn{5}{|l|}{ Education } \\
\hline$<8$ years & $4(10)$ & {$[2.8-23.7]$} & $9(22.5)$ & {$[10.8-38.4]$} \\
\hline$\geq 8$ years & $36(90)$ & {$[76.3-97.2]$} & $31(77.5)$ & [61.6- 89.2] \\
\hline \multicolumn{5}{|l|}{ Work? } \\
\hline Yes & $4(10)$ & {$[2.8-23.7]$} & $25(62.5)$ & {$[45.8-77.3]^{*}$} \\
\hline \multicolumn{5}{|l|}{ Marital status } \\
\hline Single & $32(80)$ & {$[64.4-90.9]$} & $7(17.5)$ & {$[7.3-32.8]^{*}$} \\
\hline Married & $8(20)$ & {$[9.0-35.6]$} & $33(82.5)$ & {$[67.2-92.7]^{*}$} \\
\hline \multicolumn{5}{|l|}{ Prenatal medical consultations } \\
\hline$<6$ consultations & $6(15)$ & {$[5.7-29.8]$} & $2(5.4)$ & {$[0.7-18.2]$} \\
\hline$\geq 6$ consultations & $34(85)$ & {$[70.2-94.3]$} & $35(94.6)$ & {$[81.8-99.3]$} \\
\hline
\end{tabular}

*different from adolescents $(P<0.05)$.

${ }^{1}$ Total family income / number of family members.

${ }^{2}$ Used the minimum wage relating to the period of data collection.

$\mathrm{Cl}$ : confidence interval.

For the family income variable there was a loss of nine adolescents and two adults, and for the variable prenatal medical consultations there was a loss of 3 adults. 
Regarding the anthropometric data of the newborns, it was found that $2.5 \%$ of the children generated by adolescent mothers had low birth weights $(<2,500 \mathrm{~g})$. When birth weight was classified according to gestational age, $25 \%$ of the infants born to these women were identified as being small for gestational age (SGA). Among the adult mothers, none of them gave birth to infants with a birth weight of less than 2,500 g, however, $12.5 \%$ were classified as being SGA. Additionally, the children of both the adolescent and adult mothers mostly presented

Table 2 Characterization of adolescent and adult mothers and their newborns regarding obstetric and anthropometric variables

\begin{tabular}{|c|c|c|c|c|}
\hline \multirow[t]{2}{*}{ MATERNAL ANTHROPOMETRIC VARIABLES } & \multicolumn{2}{|c|}{ Adolescents } & \multicolumn{2}{|c|}{ Adults } \\
\hline & n (\%) & $\mathrm{Cl} 95 \%$ & n (\%) & $\mathrm{Cl} 95 \%$ \\
\hline \multicolumn{5}{|l|}{ Pre-gestational nutritional status } \\
\hline Underweight & $3(7.7)$ & {$[1.6-20.9]$} & $1(2.5)$ & {$[0.1-13.2]$} \\
\hline Eutrophic & $31(79.5)$ & {$[63.5-90.7]$} & $30(75)$ & {$[58.8-87.3]$} \\
\hline Overweight & $4(10.2)$ & {$[2.9-24.2]$} & $8(20)$ & {$[9.0-35.6]$} \\
\hline Obesity & $1(2.6)$ & {$[0.1-13.5]$} & $1(2.5)$ & {$[0.1-13.2]$} \\
\hline Total & $39^{\mathrm{a}}(100)$ & & $40(100)$ & \\
\hline \multicolumn{5}{|l|}{ Adequacy of gestational weight gain } \\
\hline Insufficient & $13(33.3)$ & {$[19.1-50.2]$} & $12(31.6)$ & {$[17.5-48.6]$} \\
\hline Adequate & $15(38.5)$ & {$[23.4-55.4]$} & $10(26.3)$ & {$[13.4-43.1]$} \\
\hline Excessive & $11(28.2)$ & {$[15.0-44.9]$} & $16(42.1)$ & {$[26.3-59.2]$} \\
\hline Total & $39^{\mathrm{a}}(100)$ & & $38^{\mathrm{a}}(100)$ & \\
\hline DELIVERY AND NEWBORN ANTHROPOMETRIC VARIABLES & n (\%) & $\mathrm{Cl} 95 \%$ & n (\%) & $\mathrm{Cl} 95 \%$ \\
\hline \multicolumn{5}{|l|}{ Kind of delivery } \\
\hline Cesarean & $11(27.5)$ & {$[14.6-43.9]$} & $19(47.5)$ & {$[31.5-63.9]$} \\
\hline Vaginal & $25(62.5)$ & {$[45.8-77.3]$} & $19(47.5)$ & {$[31.5-63.9]$} \\
\hline Forceps & $4(10)$ & {$[2.8-23.7]$} & $2(5)$ & {$[0.6-16.9]$} \\
\hline Total & $40(100)$ & & $40(100)$ & \\
\hline \multicolumn{5}{|l|}{ Birth weight $(\mathbf{g})$} \\
\hline$<2500$ & $1(2.5)$ & {$[0.1-13.2]$} & $0(0)$ & {$[0.0-8.8]$} \\
\hline $2500-4000$ & $36(90)$ & {$[76.3-97.2]$} & $37(92.5)$ & {$[79.6-98.4]$} \\
\hline$>4000$ & $3(7.5)$ & {$[1.6-20.4]$} & $3(7.5)$ & {$[1.6-20.1]$} \\
\hline Total & $40(100)$ & & $40(100)$ & \\
\hline \multicolumn{5}{|l|}{ Head circumference at birth (percentile) } \\
\hline$<\mathrm{P} 3$ & $2(5)$ & {$[0.6-16.9]$} & $1(2.6)$ & {$[0.1-13.8]$} \\
\hline P3-P97 & $35(87.5)$ & {$[73.2-95.8]$} & $32(84.2)$ & {$[68.8-94.0]$} \\
\hline$>$ P97 & $3(7.5)$ & {$[1.6-20.4]$} & $5(13.2)$ & {$[4.4-28.1]$} \\
\hline Total & $40(100)$ & & $38^{\mathrm{a}}(100)$ & \\
\hline \multicolumn{5}{|l|}{ Length at birth (percentile) } \\
\hline$<\mathrm{P} 3$ & $1(2.5)$ & {$[0.1-13.2]$} & $4(10.5)$ & {$[2.9-24.8]$} \\
\hline P3-P97 & $37(92.5)$ & {$[79.6-98.4]$} & $34(89.5)$ & {$[75.2-97.1]$} \\
\hline$>$ P97 & $2(5)$ & {$[0.6-16.9]$} & $0(0)$ & {$[0.0-9.2]$} \\
\hline Total & $40(100)$ & & $38^{\mathrm{a}}(100)$ & \\
\hline \multicolumn{5}{|l|}{ Birth weight according to gestational age } \\
\hline SGA & $10(25)$ & {$[12.7-41.2]$} & $5(12.5)$ & {$[4.2-26.8]$} \\
\hline AGA & $27(67.5)$ & {$[50.9-81.4]$} & $33(82.5)$ & {$[67.2-92.7]$} \\
\hline LGA & $3(7.5)$ & {$[1.6-20.4]$} & $2(5)$ & {$[0.6-16.9]$} \\
\hline Total & $40(100)$ & & $40(100)$ & \\
\hline
\end{tabular}

${ }^{a}$ sample number of protocols completed for the variable.

SGA: small for gestational age; AGA: adequate for gestational age; LGA: large for gestational age. 
head circumference at birth within the range of adequacy (P3-P97). The same was found for length at birth (Table 2).

The relative concentrations of fatty acids identified in the total lipids of the maternal and umbilical cord plasma of the adolescents and adults is described in Table 3.

Given the correlations between fatty acids in the maternal plasma of the adolescents, total SFA was shown to correlate directly to total $t \mathrm{FA}(\mathrm{r}=0.434 ; \mathrm{P}<0.01)$ and inversely to LA $(r=-0.534 ; P<0.01)$, total EFA $(r=-0.520$; $\mathrm{P}<0.01)$, and to $\mathrm{n}-6$ PUFA $(\mathrm{r}=-0.417 ; \mathrm{P}<0.01)$. A negative correlation was also found between total $t \mathrm{FA}$ and LA $(\mathrm{r}=-0.460 ; \mathrm{P}<0.01)$, between total $t \mathrm{FA}$ and total EFA $(r=-0.419 ; \quad P<0.01)$ and $n-6$ PUFA $(r=-0.369$; $\mathrm{P}<0.05$ ), and also between relative LA and EPA levels $(\mathrm{r}=-0.450 ; \mathrm{P}<0.01)$.

In the umbilical cord plasma of the adolescents, total SFA showed a negative correlation with AA $(r=-0.486$; $\mathrm{P}<0.01)$, DHA $(\mathrm{r}=-0.402 ; \mathrm{P}<0.01)$ and total $\mathrm{n}-6$ PUFA $(\mathrm{r}=-0.360 ; \mathrm{P}<0.05)$. An inverse association was also noted between total $t$ FA and LA $(\mathrm{r}=-0.345 ; \mathrm{P}<0.05)$, as well as with total EFA $(\mathrm{r}=-0.322 ; \mathrm{P}<0.05)$ and $\mathrm{n}-6$ PUFA $(\mathrm{r}=-0.354 ; \mathrm{P}<0.05)$.

In the maternal plasma of the adult women, total SFA correlated positively to total $t \mathrm{FA} \quad(\mathrm{r}=0.488 ; \mathrm{P}<0.01)$ and negatively to LA $(\mathrm{r}=-0.620 ; \mathrm{P}<0.01)$, total EFA $(\mathrm{r}=-0.625 ; \mathrm{P}<0.01)$ and total $\mathrm{n}-6$ PUFA $(\mathrm{r}=-0.733$; $\mathrm{P}<0.01)$. Similarly, total $t$ FA correlated negatively with the relative levels of LA $(r=-0.666 ; \mathrm{P}<0.01)$, total EFA $(\mathrm{r}=-0.652 ; \mathrm{P}<0.01)$ and $\mathrm{n}-6$ PUFA $(\mathrm{r}=-0.699 ; \mathrm{P}<0.01)$.

As for the umbilical cord plasma of the adults, total $t$ FA content correlated inversely to relative AA $(\mathrm{r}=-0.466$; $\mathrm{P}<0.05)$ and total $\mathrm{n}-6$ PUFA $(\mathrm{r}=-0.449 ; \mathrm{P}<0.05)$ levels. An additional inverse relationship was observed between the proportions of LA and EPA $(r=-0.488 ; \mathrm{P}<0.01)$.

Among all fatty acids identified in the maternal plasma, only DHA in the adolescents correlated with the anthropometric data of their respective newborns, with a positive correlation found between this fatty acid and birth weight $(\mathrm{r}=0.374 ; \mathrm{P}<0.05)$ and head circumference $(\mathrm{r}=0.372 ; \mathrm{P}<0.05)$ (Figure 1).

Table 3 Composition of fatty acids (\%) in maternal and umbilical cord plasma of adolescent and adult Brazilian mothers

\begin{tabular}{|c|c|c|c|c|}
\hline \multirow[t]{2}{*}{ Fatty acids } & \multicolumn{2}{|c|}{ Maternal plasma } & \multicolumn{2}{|c|}{ Umbilical Cord plasma } \\
\hline & Adolescents & Adults & Adolescents & Adults \\
\hline \multicolumn{5}{|l|}{ Monounsaturated } \\
\hline C18:1 (n-9) cis & $17.3 \pm 5.2$ & $18.0 \pm 3.8$ & $15.7 \pm 2.4$ & $17.8 \pm 7.4$ \\
\hline C18:1 (n-9) trans & $0.7 \pm 0.6$ & $0.6 \pm 0.4$ & $0.5 \pm 0.5^{\mathrm{a}}$ & $0.5 \pm 0.5$ \\
\hline \multicolumn{5}{|l|}{ Essential fatty acids } \\
\hline C18:2 n-6 (linoleic acid) & $31.3 \pm 3.9$ & $31.4 \pm 6.0$ & $12.5 \pm 2.1^{\mathrm{a}}$ & $12.8 \pm 4.8^{\mathrm{b}}$ \\
\hline C18:3 n-3 (a-linolenic acid) & $0.2 \pm 0.3$ & $0.2 \pm 0.1$ & $0.5 \pm 0.6$ & $0.5 \pm 1.3$ \\
\hline \multicolumn{5}{|c|}{ Long-chain polyunsaturated fatty acids } \\
\hline C20:4 n-6 (AA) ${ }^{1}$ & $5.5 \pm 1.2$ & $4.6 \pm 2.4^{\mathrm{a}}$ & $13.1 \pm 2.4^{\mathrm{a}}$ & $10.7 \pm 4.0^{\mathrm{b}, \mathrm{c}}$ \\
\hline$C 20: 5 n-3(E P A)^{2}$ & $0.4 \pm 0.2$ & $0.4 \pm 0.2$ & $0.6 \pm 0.3^{\mathrm{a}}$ & $1.1 \pm 0.8^{\mathrm{b}, \mathrm{c}}$ \\
\hline $\mathrm{C} 22: 6 \mathrm{n}-3(\mathrm{DHA})^{3}$ & $1.3 \pm 0.5$ & $1.5 \pm 0.6$ & $2.8 \pm 0.7^{\mathrm{a}}$ & $2.7 \pm 1.0^{b}$ \\
\hline MFA Total ${ }^{4}$ & $20.3 \pm 4.7$ & $20.0 \pm 3.9$ & $21.2 \pm 3.8$ & $21.8 \pm 7.2$ \\
\hline EFA Total ${ }^{5}$ & $31.5 \pm 3.9$ & $31.5 \pm 6.0$ & $12.9 \pm 2.3^{\mathrm{a}}$ & $13.0 \pm 4.8^{b}$ \\
\hline n-6 PUFA Total ${ }^{6}$ & $37.7 \pm 4.5$ & $35.8 \pm 5.9$ & $26.9 \pm 2.4^{a}$ & $23.4 \pm 5.7^{b, c}$ \\
\hline n-3 PUFA Total ${ }^{7}$ & $1.8 \pm 0.7$ & $1.9 \pm 0.6$ & $3.8 \pm 1.2^{\mathrm{a}}$ & $3.6 \pm 1.9^{b}$ \\
\hline PUFA-LC Total $^{8}$ & $7.2 \pm 1.4$ & $6.3 \pm 2.8^{a}$ & $16.3 \pm 2.7^{\mathrm{a}}$ & $14.0 \pm 4.4^{b, c}$ \\
\hline Saturated Total $^{9}$ & $35.9 \pm 3.3$ & $39.7 \pm 4.9^{a}$ & $44.5 \pm 3.8^{\mathrm{a}}$ & $46.6 \pm 6.2^{b}$ \\
\hline Trans Total ${ }^{10}$ & $0.8 \pm 0.6$ & $0.9 \pm 0.8$ & $0.5 \pm 0.5^{a}$ & $0.8 \pm 0.9$ \\
\hline
\end{tabular}

Values presented as mean and standard deviation $(n=40)$.

${ }^{1} \mathrm{AA}$ - archidonic acid; ${ }^{2} \mathrm{EPA}$ - eicosapentaenoic acid; ${ }^{3} \mathrm{DHA}$ - docosahexaenoic acid; ${ }^{4} \mathrm{MFA}$ total: total of monounsaturated fatty acid - It includes all the cis position; ${ }^{5}$ EFA total: total of essencial fatty acids - It includes C18:3n-3 and C18:2 n-6; ${ }^{6} n-6$ PUFA total: total of n-6 polyunsaturated fatty acids - It includes C18:2 $n-6, C 18: 3 n-6, C 20: 2 n-6, C 20: 3 n-6, C 20: 4 n-6$ and C22:4 n-6; ${ }^{7} n-3$ PUFA total: total of n-3 polyunsaturated fatty acids - It includes C18:3 n-3, C20:5 n-3, C22:5 n-3 and C22:6 n-3; ${ }^{8}$ PUFA-LC total: total of long-chain polyunsaturated fatty acids - It includes EPA, DHA and AA; ${ }^{9}$ saturated total - It includes C14:0, C15:0, C16:0 and C18:0; ${ }^{10}$ Trans total: It includes C 18:1 n-9 trans and C 18:2 n-6 trans.

${ }^{a}$ different from maternal plasma of adolescents mothers: $P<0.05$.

b different from maternal plasma of adults mothers: $P<0.05$.

'different from umbilical cord plasma of adolescents mothers: $\mathrm{P}<0.05$. 


\section{Discussion}

According to data provided by the Brazilian Ministry of Health $(\mathrm{MH})$, approximately $21 \%$ of all live births in 2007 were born of adolescents [21]. Pregnancy in this age group has been identified as a public health problem in Brazil and other countries, mainly because of possible adverse outcomes for both mother and child [22]. In this study we asked if there are differences between the fatty acid profile in maternal and fetal biological compartments of adolescent and adult mothers and if there are relationship between this profile and the growth parameters of newborns in Brazilian pregnant woman.

A large percentage of the pregnant adolescents and adults evaluated had at least six prenatal medical visits, meeting the recommendations of the MH [23]. This may have contributed to the greater proportion of newborns with adequate anthropometric nutritional status at birth in both age groups, confirming the positive association between quality of prenatal care and good outcome for
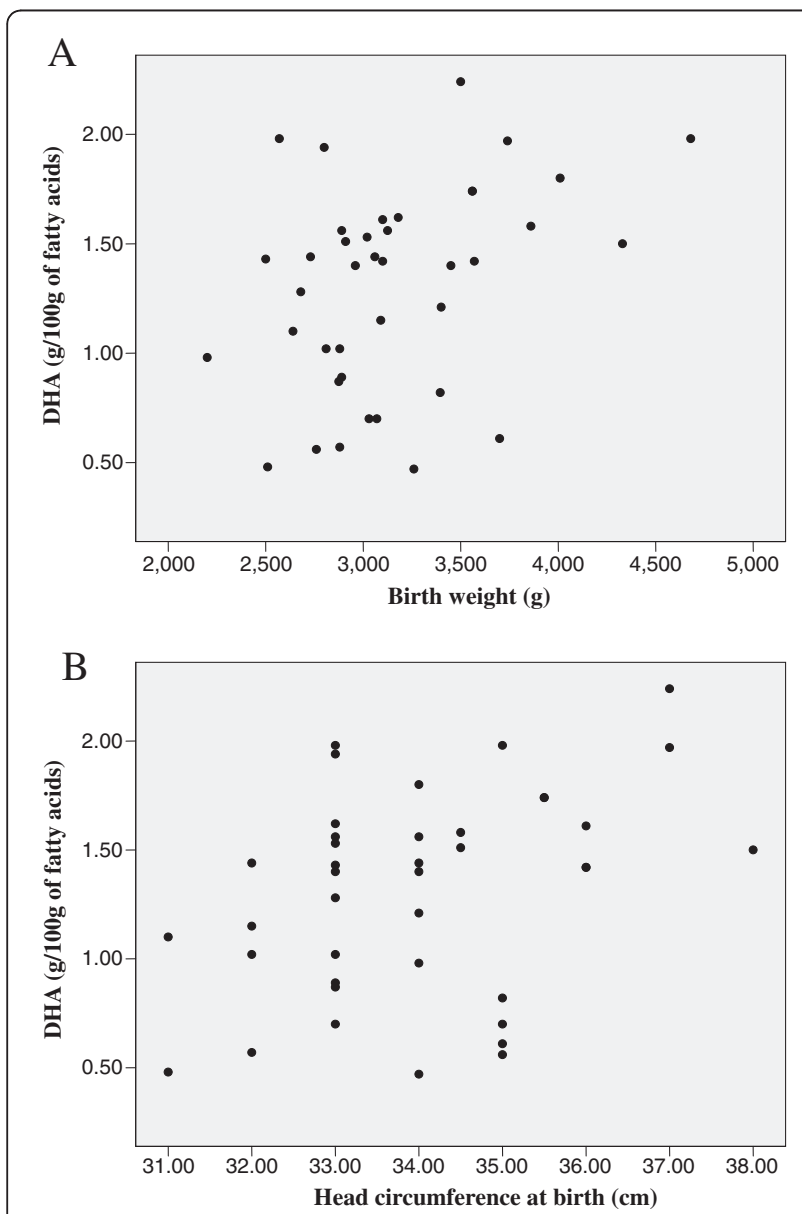

Figure 1 Correlation between plasma DHA concentration of adolescent mothers and birth weight of their newborns $(r=0.374$; $P<0.05)(1 \mathrm{~A})$. Correlation between plasma DHA concentration of adolescent mothers and head circumference at birth of their newborns $(r=0.372$; $P<0.05)(1 \mathbf{B})$. the newborns as previously proposed in others studies [20,24-26].

It has been reported that the maternal and fetal fatty acid status varies widely and is influenced by the mother's dietary lipid intake [6]. However, we found that relative concentrations of EFA in the maternal and umbilical cord plasma of both adolescents and adults were equivalent to those observed by Pankiewicz et al. [27], which were also identified for total lipids in the maternal and umbilical cord plasma of mothers.

We observed lower concentrations of LA and ALA and greater proportions of AA, EPA and DHA in the umbilical cord plasma than the maternal plasma in both age groups. These findings are consistent with the results of most previous studies which had also evaluated relative concentrations of FAs in these biological compartments [27-30]. These differences could be accounted for the presence of the placental membrane proteins which boost LC-PUFA uptake in such a way that these fatty acids are transported more efficiently than the shorter-chain variety [31]. The existence of a specific transport system for fatty acids, which includes multiple proteins, facilitates the preferential transport of LC-PUFAs via the placenta and proves to be the mechanism that allows the needs of the fetus to be met [32].

In our study the proportion of SFA was significantly higher in the umbilical cord plasma than in the maternal plasma. This is in agreement with a previous study [33]. The intense fetal lipogenesis which is reflected in the active synthesis of SFA [34] could provide the biochemical basis for these results.

Elias \& Innis [29] found that dietary $t$ FA intake related significantly and positively to $t$ FA concentrations in the plasma of pregnant women. In addition, these authors found a significant relationship in the proportions of this fatty acid in maternal plasma and that of the umbilical cord. These findings are consistent with our results, which revealed similar concentrations of $t$ FAs in the maternal and fetal plasma of the adult group. Additionally, other authors suggest that placental transfer of $t$ FAs occurs selectively, because they are found in a greater percentage in the maternal plasma than the umbilical cord plasma [33,35], which is in agreement with our results for the adolescent mothers.

Both the maternal plasma and the umbilical plasma of the adolescents presented higher proportions of AA when compared to the adults. We could not find similar results in existing literature; however, one can surmise that distinct dietary intake patterns may exist between the different groups. On the other hand, considering the fundamental role that AA plays in promoting growth during the fetal and postnatal period [36], the assumption can be made that the difference found in levels of this LC-PUFA between age groups could be due to the 
adolescents' stage of growth and development. Indeed, this hypothesis demands further research.

Examining the umbilical cord plasma, we found that EPA content was higher in the adults than in the adolescents. These results suggest that, comparatively, the higher AA status of the adolescents may affect motherfetal n-3 LC-PUFA transfer, contributing to the lesser proportion of EPA in the umbilical cord plasma of this age group [37]. Previous report had pointed out that despite the scarcity of information regarding the impact of pregnancy and lactation on EFA and LC-PUFA status in adolescents, these two physiological situations may affect the status of these fatty acids differently in adults and adolescents [38].

With regard to the correlations between fatty acids in the maternal plasma of adolescents and adults, we found that total $t$ FA and SFA were inversely correlated to relative concentrations of LA and to total EFA and n-6 PUFA levels. However, total $t \mathrm{FA}$ and SFA correlated positively with each other. These results can be justified by the mother's habitual consumption of dietary sources of these fatty acids [38]. An increase in consumption of processed products and fast food, which carry elevated levels of SFAs and $t$ FAs, is generally accompanied by a reduction in consumption of $n-6$ and $n-3$ FAs food sources [17]. In addition, a high intake of $t$ FAs may alter maternal LC-PUFA status by reducing synthesis of AA, EPA and DHA fatty acids, especially by inhibiting the $\Delta 6$ desaturase enzyme, decreasing availability of these fatty acids to the fetus and, thus, compromising intrauterine development [39]. Proper nutritional guidance during the prenatal stage could be a strategy to overcome the potential metabolic harms of these poor dietary practices [16].

Analysis of relative FA levels in the total lipids of the adolescent maternal plasma further revealed a negative correlation between LA and EPA proportions. In this regard, it is noteworthy that the $\Delta 5$ and $\Delta 6$ desaturase enzymes that act on PUFA desaturation have a greater affinity with the more unsaturated substrates, i.e., the $n-3$ family, followed by the n- 6 and n- 9 families. However, an increase in LA availability for these enzymes may impair desaturation of ALA to EPA and to DHA [3].

The standard diet of pregnant adolescents and adults in Brazil shows a prevalence of $n-6$ series fatty acid food sources, like vegetable oils, mainly soy oil, as opposed to $\mathrm{n}-3$ sources, like fish and fish oil, resulting in a high $\mathrm{n}-6$ / $\mathrm{n}-3$ ratio in their diet $[37,40]$.

Consistent with the inhibitory effect of $t \mathrm{FA}$, as well as the fact that concentrations of this fatty acid in the fetal plasma are determined by maternal diet, a negative correlation was found between total $t \mathrm{FA}$ and total EFA and n-6 PUFA in the umbilical cord plasma of the adolescents, following the pattern of the maternal plasma. In the case of the cord plasma of the adult mothers, total $t$ FA was shown to be inversely associated with AA and total n-6 PUFA, also similar to the maternal plasma of this group. Elias \& Innis [29] observed an inverse relationship between dietary $t \mathrm{FA}$ and $\mathrm{AA}$ in the cholesterol esters of the umbilical cord plasma, as well as between $t$ FA and DHA in the triacylglycerols, also in the umbilical cord plasma. It has been reported that trans isomers hamper placental transfer of LC-PUFA as they compete for the fatty acid-binding protein of the placental plasma membrane (FABPpm), lowering the fetal LC-PUFA status [41].

Our results do not indicate that $t \mathrm{FAs}$ interfere with the growth parameters of the newborn. These findings are consistent with data from previous studies which do not found an association between trans isomers and restricted intrauterine growth [12,13,29]. However, regarding n-3 LC-PUFA series, the relative concentration of DHA in the plasma of the adolescents associated positively with the weight and head circumference of the newborns. Recently, another study carried out by our group [42] found a positive and significant association between total n-3 PUFA in maternal milk and weight and length gain in preterm babies. This suggests that n-3 fatty acids have a greater influence on the proper development of the newborn, especially in situations of greater nutritional risk, like adolescent pregnancy and preterm birth.

\section{Conclusion}

The importance of LC-PUFA's during pregnancy is well documented $[1,8,43]$. The positive association between DHA and head circumference is evidence that this fatty acid is related to brain development. It was also noted that priority transfer of AA, EPA and DHA across the placenta occurs in both adolescents and adults. However, the differences in concentrations of these fatty acids in the maternal and umbilical cord plasma between adolescents and adults, indicates a need for research to identify the nature of the metabolic and physiological processes that justify these differences.

\section{Methods}

\section{Participant eligibility criteria and selection}

This is an observational, cross-sectional analytical study [44]. We selected 40 pregnant adolescents (between 15 and 19 years of age) and 40 pregnant adults (between 20 and 40 years of age) in two public maternities, in the city of Rio de Janeiro, Brazil. None of the subjects were smokers, pregnant with twins, drug or alcohol users, or chronic disease sufferers, nor were there any fetal complications. The protocol used to obtain socio-economic and obstetric data was developed and tested beforehand. 
The project was approved by the Research Ethics Committees of two public maternity wards in the city of Rio de Janeiro, Brazil, in accordance with National Health Council resolution 196/96 [45].

\section{Assessment of maternal nutritional status}

Pre-gestational weight (PGW) and height measurements were taken on the first visit to antenatal care, prior to the $14^{\text {th }}$ gestational week [46]. The final weight of pregnancy (before delivery) was measured on admission for delivery.

To evaluate the pre-gestational nutritional status of the pregnant adolescents, Body Mass Index (BMI) cutoff points were used that were specific for age and female gender [47].

The pre-gestational nutritional status of the pregnant adults was assessed on the basis of BMI cut-off points recommended by the Institute of Medicine (IOM), 2009 [48].

The adequacy of gestational weight gain was assessed according to IOM-recommended weight gain ranges (2009) [48] within the following pre-gestational BMI categories: underweight, $12.5-18.0 \mathrm{~kg}$; eutrophic, 11.5$16.0 \mathrm{~kg}$; overweight, 7.0-11.5 kg; and obesity, $5.0-9.0 \mathrm{~kg}$ (adults) and $7.0-9.1 \mathrm{~kg}$ (adolescents, as proposed by GUTIERREZ \& KING) [49].

\section{Assessment of nutritional status of newborn}

The classification of low birth weight (BW) was defined according to the World Health Organization established cut-off point [50] of weight less than 2,500 g. To classify BW according to gestational age, we used the Alexander graph [51]. For length and head circumference at birth, the curves published by the World Health Organization in 2006 [52] and 2007 [53], respectively, were used as references.

\section{Collection and storage of biological material}

A 5-mL sample of maternal blood was taken intravenously by a qualified professional. Blood from the umbilical cord was collected by hand-milking before expulsion of the placenta. Both samples were collected using tubes containing $1 \mathrm{~g} \mathrm{Na2-EDTA/L}$. The material underwent centrifugation (3,500 rpm for 15 minutes) to separate and extract the plasma, which was transferred to eppendorf tubes that were then stored at a temperature of $-70^{\circ} \mathrm{C}$ until the time of analysis.

\section{Quantification of fatty acids in total plasma lipids}

The lipids in the samples were extracted, saponified and methylated according to the method described by Lepage \& Roy [54]. Fatty acid esters were quantified through gas-liquid chromatography using the Perkin Elmer autosystem XL chromatograph, equipped with a flame ionization detector and Turbochrom software. Fatty acids were separated using an SP 2560 capillary column (Supelco, USA), with $100 \mathrm{~m} \times 0.25 \mathrm{~mm} \times$ $0.20 \mu \mathrm{m}$ measurements. The chromatographic conditions were similar to those described by Tinoco et al. [55]. The esters were identified by comparing their retention times to known standards (Sigma, Supelco). Results were expressed as mean \pm standard deviation of weight percentage ( $\mathrm{g} / 100 \mathrm{~g}$ of total fatty acids).

\section{Statistical analysis}

The Skewness test was used to evaluate the symmetry of continuous variables. A confidence interval of $95 \%$ was used to compare frequencies between categorical variables. The paired $t$ test and Wilcoxon test were used to compare data with parametric and nonparametric distributions, respectively, in the same group. When comparing data with symmetrical and nonsymmetrical distributions between the groups, the independent $t$ test and Mann-Whitney test were used, respectively. To assess correlations between continuous variables, we used the Pearson or Spearman correlation coefficients, depending on the nature of the variables (normal distribution or not, respectively). To perform statistical analysis, we used the Statistical Packages for Social Sciences (SPSS) version 13.0 and Epi-Info version 6.0. Values of $\mathrm{P}<0.05$ were considered to be statistically significant.

\section{Abbreviations}

EFAs: Essential fatty acids; LA: Linoleic acid; ALA: a-linolenic acid; LC-PUFA: Long-chain polyunsaturated fatty acids; AA: Archidonic acid: EPA: Eicosapentaenoic acid; DHA: Docosahexaenoic acid; tFA: Trans fatty acids; SFA: Saturated fatty acids; PGW: Pre-Gestational Weight; BMI: Body Mass Index; IOM: Institute of Medicine; BW: Birth weight; SGA: Small for gestational age; $n-6$ PUFA: $n-6$ polyunsaturated fatty acids; MH: Brazilian Ministry of Health; $n-3$ LC-PUFA: $n-3$ long-chain polyunsaturated fatty acids.

Competing interests

The authors declare that they have no competing interests.

\section{Authors' contributions}

ORCO participated in the design of the study, acquisition of data, helped to perform the statistical analysis and drafted the manuscript. MGS participated in the acquisition of data and helped to perform the statistical analysis. FSS participated in the design of the study and in the acquisition of data. FDC carried out the quantification of fatty acids in total plasma lipids. FLCS participated in the design of the study and helped to draft the manuscript. GW participated in the design of the study and helped to perform the statistical analysis. MGTC conceived of the study, participated in its design and coordination and helped to draft the manuscript. All authors read and approved the final manuscript.

\section{Acknowledgements}

The authors gratefully acknowledge Vilma Blondet de Azeredo, Kelse Tibau de Albuquerque and Elisa Maria de Aquino Lacerda to help in the design of the study and to make contributions in the interpretation of data. The work was supported by National Counsel of Technological and Scientific Development Fund (CNPq- Conselho Nacional de Desenvolvimento Científico e Tecnológico).

\section{Author details}

${ }^{1}$ Nutritional Biochemical Laboratory, Josué de Castro Institute of Nutrition, Federal University of Rio de Janeiro, Rio de Janeiro, Brazil. ${ }^{2}$ Department of 
Social and Applied Nutrition, Josué de Castro Institute of Nutrition, Federal University of Rio de Janeiro, Rio de Janeiro, Brazil. ${ }^{3}$ Instituto de Nutrição Josué de Castro, UFRJ - Laboratório de Bioquímica Nutricional, Av. Brigadeiro Trompowski, s/n - CCS, Bloco J, $2^{\circ}$ andar, Cidade Universitária, Ilha do Fundão, Cep.: 21941-590, Rio de Janeiro, Brazil.

Received: 22 February 2012 Accepted: 8 November 2012 Published: 15 November 2012

\section{References}

1. Innis SM: Fatty acids and early human development. Early Hum Dev 2007, 83:761-766

2. Calder PC: N-3 polyunsaturated fatty acids, inflammation and immunity: pouring oil on troubled waters or another fishy tale? Nutr Res 2001, 21:309-341.

3. Innis SM: Perinatal biochemistry and physiology of long-chain polyunsaturated fatty acids. J Pediatr 2003, 143:1-8.

4. Innis SM: Essential fatty acid transfer and fetal development. Placenta 2005, 26:570-575.

5. Heird WC, Lapillonne A: The role of essential fatty acids in development. Annu Rev Nutr 2005, 25:549-571.

6. Innis SM: Dietary omega 3 fatty acids and the developing brain. Brain Res 2008, 1237:35-43.

7. Koletzko B, Cetin I, Brenna JT: Dietary fat intakes for pregnant and lactating women. Br J Nutr 2007, 98:873-877.

8. Jensen CL: Effects of $n-3$ fatty acids during pregnancy and lactation. Am Clin Nutr 2006, 83:1452-1457.

9. Ghebremeskel K, Crawford MA, Lowy C, Min Y, Thomas B, Golfetto I, Bitsanis D, Costeloe $\mathrm{K}$ : Arachidonic and docosahexaenoic acids are strongly associated in maternal and neonatal blood. Eur J Clin Nutr 2000, 54:50-56.

10. Duttaroy AK: Transport of fatty acids across the human placenta: a review. P Lip Res 2009, 48:52-61.

11. Stender S, Dyerberg J: Influence of trans fatty acids on health. Ann Nutr Metab 2004, 48:61-66.

12. Dirix CEH, Kester AD, Hornstra G: Associations between neonatal birth dimensions and maternal essential and trans fatty acid contents during pregnancy and at delivery. Brit J Nutri 2008, 101:399-407.

13. van Eijsden M, Hornstra G, van der Wal MF, Vrijkotte TG, Bonsel GJ: Maternal essential fatty acid status early in pregnancy and term birthweight: a prospective cohort study. Am J Clin Nutr 2008, 87:887-895.

14. Chiara VL: Nutricional evaluation of adolescents as a means of prevention of coronary heart disease, PhD thesis. State University of Rio de Janeiro, Institute of Social Medicine. 2000

15. Andrade RG, Pereira RA, Sichieri R: Food intake in overweight and normalweight adolescents in the city of Rio de Janeiro. Cad Saude Publica 2003, 19:1485-1495.

16. Barros DC, Pereira RA, Gama SGN, Leal MC: Food consumption by pregnant adolescents in Rio de Janeiro, Brazil. Cad Saude Publica 2004 20(Suppl 1):121-129.

17. Carvalho CMRG, Nogueira AMT, Teles JBM, Paz SMR, Sousa RML: Food consumption by adolescents enrolled in a private high school in the city of Teresina, Piauí, Brazil. Rev Nutri Campinas 2001, 14:85-93.

18. Ziwian Zப: Nutrition Education in Adolescence. Hig Aliment 1999, 13:85-87.

19. Lenders CM, McElrath TF, Scholl TO: Nutrition in adolescent pregnancy. Curr Opin Pediatr 2000, 12:291-296.

20. Gama SGN, Szwarcwald CL, Leal MC: Pregnancy in adolescence, associated factors, and perinatal results among low-income post-partum women. Cad Saude Publica 2002, 18:153-161.

21. Ministry of Health - MH - Brazil: Vital statistics; 2007. Computer Department of SUS - DATASUS [online] 2007. [http://w3.datasus.gov.br/datasus/index]

22. Furlan JP, Guazzell CAF, Papa ACS, Quintino MP, Soares RVP, Mattar R: The influence of nutritional status of pregnant adolescents on parturition and newborn's weight. Rev Bras Ginecol Obstet 2003, 25:625-630

23. Ministry of Health - MH - Brazil: Technical Manual - Prenatal and postpartum: qualified and humanized care, Sexual and Reproductive Rights. Brasilia-DF. 2006 [http://portal.saude.gov.br/portal/arquivos/pdf/ manual_puerperio_2006.pdf]

24. Visintainer PF, Uman J, Horgan $\mathrm{K}$, Ibalt $\mathrm{A}$, Verma $\mathrm{U}$, Tejani $\mathrm{N}$ : Reduce risk of low births among indigent women receiving care from nurse-midwives. J Epidemiol Community Health 2000, 54:233-238.
25. Kassar SB, Gurgel RQ, Albuquerque MFM, Barbieri MA, Lima MC: Infants' birth weight born from adolescents as compared to those of young adult women. Rev Bras Saúde Matern Infant 2005, 5:293-299.

26. Santos GHN, Martins MG, Sousa MS: Teenage pregnancy and factors associated with low birth weight. Rev Bras Ginecol Obstet 2008, 30:224-231.

27. Pankiewicz E, Cretti A, Ronin-Walknowska E, Czeszynska MB, Konefa H, Hnatyszyn G: Maternal adipose tissue, maternal and cord blood essential fatty acids and their long-chain polyunsaturated derivatives composition after elective caesarean section. Early Hum Dev 2007, 83:459-464.

28. Berghaus TM, Demmelmair H, Koletzko B: Essential fatty acids and their long chain polyunsaturated metabolites in maternal and cord plasma triglycerides during late gestation. Biol Neonate 2000, 77:96-100.

29. Elias SL, Innis SM: Infant plasma trans, $n-6$, and $n-3$ fatty acids and conjugated linoleic acids are related to maternal plasma fatty acids, length of gestation, and birth weight and length. Am J Clin Nutr 2001, 73:807-814

30. Larqué E, Demmelmair H, Berger B, Hasbargen U, Koletzko B: In vivo investigation of the placental transfer of (13) C-labeled fatty acids in humans. J Lipid Res 2003, 44:49-55.

31. Tobin KAR, Johnsen GM, Staff AC, Duttaroy AK: Long-chain polyunsaturated fatty acid transport across human placental choriocarcinoma (BeWo) cells. Placenta 2009, 30:41-47.

32. Hanebutt FL, Demmelmair H, Schiessl B, Larqué E, Koletzko B: Long-chain polyunsaturated fatty acid (LC-PUFA) transfer across the placenta. Clin Nutr 2008, 27:685-693.

33. Vlaardingerbroek $\mathrm{H}$, Hornstra G: Essential fatty acids in erythrocyte phospholipids during pregnancy and at delivery in mothers and their neonates: comparison with plasma phospholipids. Prostaglandins Leukot Essent Fatty Acids 2004, 71:363-374.

34. Herrera E: Implications of dietary fatty acids during pregnancy on placental, fetal and postnatal development - a review. Placenta 2002, 23:9-19.

35. Mojska H: Influence of trans fatty acids on infant and fetus development. Acta Microbiol Pol 2003, 52:67-74.

36. Xiang $M$, Harbige LS, Zetterstrom R: Breast milk levels of zinc and omega- 6 polyunsaturated fatty acids and growth of healthy Chinese infants. Acto Paediatr 2007, 96:387-390.

37. Pontes PV, Torres AG, Trugo NMF, Fonseca VM, Sichieri R: N-6 and $n-3$ longchain polyunsaturated fatty acids in the erythrocyte membrane of Brazilian preterm and term neonates and their mothers at delivery. Prostaglandins Leukot Essent Fatty Acids 2006, 74:117-123.

38. Torres AG, Trugo NMF: Evidence of inadequate docosahexaenoic acid status in Brazilian pregnant and lactating women. Rev Saude Publica 2009, 43:359-368.

39. Chiara VL, Silva R, Jorge R, Brasil AP: Trans fatty acids: cardiovascular diseases and maternal-child health. Rev Nutr 2002, 15:341-349.

40. Meneses F, Ney JG, Torres AG, Trugo NMF: Erythrocyte membrane and plasma non-esterified $n-3$ and $n-6$ polyunsaturated fatty acids of pregnant and nonpregnant Brazilian adolescents. Prostaglandins Leukot Essent Fatty Acids 2009, 80:137-142.

41. Campbell FM, Gordon MJ, Dutta-Roy AK: Preferential uptake of long chain polyunsaturated fatty acids by isolated human placental membranes. Mol Cell Biochem 1996, 155:77-83.

42. McIntire DD, Bloom SL, Casey BM: Birth weight in relation to morbidity and mortality among newborn infants. N Engl J Med 1999, 340:1234-1238.

43. Uauy R, Mena P, Wegher B, Nieto S, Salem N Jr: Long chain polyunsaturated fatty acid formation in neonates: effect of gestational age and intrauterine growth. Pediatr Res 2000, 47:127-135.

44. Hennekens $\mathrm{CH}$, Buring JE: Epidemiology in medicine. 1st edition. Boston/ Toronto: Little, Brown and Company; 1987

45. National Health Council- Brazil: Resolution n 196/96 - guidelines and rules for research involving human. Bioethics 1996, 4:415-425 [http://www.ufrgs.br/bioetica/res19696.htm]

46. Ministry of Health - Brazil: Prenatal care - Technical Manual, Brasília-DF; 2000 [http://bvsms.saude.gov.br/bvs/publicacoes/cd04_11.pdf]

47. World Health Organization - WHO: Growth reference data for 5-19 years, WHO [online]. 2007 [http://www.who.int/growthref/en/

48. Institute of Medicine - IOM: Weight Gain During Pregnancy: Reexamining the Guidelines, National Academy of Science. Washington: National Academy Press; 2009. 
49. Gutierrez $Y$, King JC: Nutrition during teenage pregnancy. Pediatr Ann 1993, 22:99-108

50. World Health Organization - WHO: Physical status: the use and interpretation of anthropometry, Technical Report Series, 854. Geneva. 1995.

51. Alexander GR, Himes JH, Kaufman RB, Mor J, Kogan M: A United States national reference for fetal growth. Obstet Gynecol 1996, 87:163-168.

52. World Health Organization - WHO, Onis M, Garza C, Onyango AW, Martorell R: WHO Child Growth Standards. Acta Paediatr 2006, 95(Suppl 450):1-103.

53. World Health Organization - WHO: Child Growth Standards, Head circumference-for-age, arm circumference-for-age, triceps skinfold-for-age and subscapular skinfold-for-age: Methods and development. Geneva: WHO; 2007.

54. Lepage G, Roy CC: Direct transesterification of all classes of lipids in a one-step reaction. J Lipid Res 1986, 27:114-120.

55. Tinoco SMB, Sichieri R, Setta CL, Moura AS, Tavares do Carmo MG: Trans fatty acids from milk of Brazilian mothers of premature infants. J Paediatr Child Health 2008, 44:50-56.

doi:10.1186/1476-511X-11-157

Cite this article as: Oliveira et al:: Composition of fatty acids in the maternal and umbilical cord plasma of adolescent and adult mothers: relationship with anthropometric parameters of newborn. Lipids in Health and Disease 2012 11:157.

\section{Submit your next manuscript to BioMed Central and take full advantage of:}

- Convenient online submission

- Thorough peer review

- No space constraints or color figure charges

- Immediate publication on acceptance

- Inclusion in PubMed, CAS, Scopus and Google Scholar

- Research which is freely available for redistribution 